\title{
Low Skepticism and Positive Attitudes About Advance Care Planning Among African Americans: a National, Mixed Methods Cohort Study
}

\author{
Lauren Jodi Van Scoy, MD ${ }^{1,2,3}$ (D), Michael J. Green, $M D^{1,2}$, Pamela D. Witt, $A A^{7}$, \\ Cindy Bramble 4 , Christopher Richardson, $M A^{4}$, Irene Putzig, $M S^{4}$, Olubukola Toyobo, $B S^{5}$, \\ Emily Wasserman, MAS ${ }^{3}$, Vernon M. Chinchilli, PhD ${ }^{3}$, Amy Tucci, BS ${ }^{4}$, and \\ Benjamin H. Levi, MD, $P h D^{2,6}$
}

\begin{abstract}
'Department of Medicine, Penn State College of Medicine, Hershey, PA, USA; '2Department of Humanities, Penn State Milton S. Hershey Medical Center, Penn State College of Medicine, Hershey, PA, USA; ${ }^{3}$ Department of Public Health Sciences, Penn State Milton S. Hershey Medical Center, Penn State College of Medicine, Hershey, PA, USA; ${ }^{4}$ Hospice Foundation of America, Washington, DC, USA; ${ }^{5}$ Penn State College of Medicine, Penn State Milton S. Hershey Medical Center, Hershey, PA, USA; 'Department of Pediatrics, Penn State Milton S. Hershey Medical Center, Penn State College of Medicine, Hershey, PA, USA.
\end{abstract}

BACKGROUND: African Americans have low engagement in advance care planning (ACP). This has been attributed to healthcare distrust and skepticism about ACP. A better understanding of these attitudes is needed to address health disparities related to end-of-life care.

OBJECTIVE: To explore the ACP-related values and beliefs of diverse African American communities across the USA and then the perceived value of an inexpensive end-of-life conversational game.

DESIGN: Prospective, convergent, mixed methods cohort study involving fifteen underserved, African American communities across the USA.

PARTICIPANTS: Of the 428 who attended events at purposively sampled sites, $90 \%$ consented to the research; $37 \%$ participated in one of 15 focus groups $(n=141)$.

INTERVENTION: An end-of-life conversation game, played in groups of 4-6.

MAIN MEASURES: The validated, 7-item ACP values and beliefs questionnaire (scaled $7=$ least skeptical, $49=$ most skeptical) was administered pre-game. Post-game focus groups explored perceptions about ACP and the intervention.

KEY RESULTS: Participants had positive attitudes (low skepticism) about ACP with a median score of 12.00 (7.00, 20.00). Values and beliefs did not significantly differ by geographical region; however, rural areas were observed to be slightly more skeptical than urban areas (median score 14.00 vs. 11.00, $p=0.002$ ). Themes from focus groups converged with survey data showing participants valued the ACP process and consider further engagement in ACP to be worthwhile. Subthemes emphasized the need for and value of ACP.

$\overline{\text { Prior Presentations Some aspects of this work were presented at the }}$ American Thoracic Society Meeting in Dallas, Texas in 2019.

Electronic supplementary material The online version of this article (https://doi.org/10.1007/s11606-020-06224-z) contains supplementary material, which is available to authorized users.

Received April 29, 2020

Accepted September 7, 2020

Published online September 18, 2020
CONCLUSIONS: Skepticism about ACP may contribute to low rates of ACP engagement in underserved African American communities. The positive attitudes uncovered in our study either negate previous findings or suggest reduced skepticism.

TRIAL REGISTRATION: This study has been registered at clinicaltrials.gov (NCT03456921)

KEY WORDS: advance care planning; End-of-life care; Underserved communities; Health disparities

J Gen Intern Med 36(3):705-12

DOI: $10.1007 / \mathrm{s} 11606-020-06224-\mathrm{z}$

(c) Society of General Internal Medicine 2020

\section{INTRODUCTION}

High-quality end-of-life care includes providing culturally sensitive medical treatment that is aligned with a patient's actual values and preferences. ${ }^{1}$ It is well established that African American patients receive lower quality end-of-life care than White patients, a health disparity that has persisted for many years. ${ }^{2-5}$ Compared with Whites, African Americans are more likely to undergo aggressive, unwanted treatments and less likely to utilize hospice resources at the end of life. ${ }^{6-10}$ One reason for this is the low rate of engagement in advance care planning (ACP) by African American communities. 2, 11 $\mathrm{ACP}$ is a process that involves discussing end-of-life treatment preferences and documenting those wishes in an advance directive. Effective ACP can help minimize the delivery of unwanted medical treatment at the end of life $^{7,8}$ and may help to reduce end-of-life costs by up to $36 \% .^{12-15}$ While recent data show that up to $60 \%$ of all US adults have engaged in $\mathrm{ACP},{ }^{16,17}$ fewer than 25\% of African Americans have done so. $^{2-6,16,18,19}$ Many have posited that this lack of engagement stems in part from distrust of the healthcare system, given decades of discriminatory misconduct towards underserved populations, along with negative attitudes about ACP. ${ }^{20,} 21$ 
That said, evidence supporting this claim has been conflicting and the degree to which African Americans are skeptical of the ACP process has not been clearly established. ${ }^{5}$ The objective of this study was to better understand the attitudes of African Americans toward ACP. This was achieved via a mixed methods exploration of skepticism toward ACP among a national sample of individuals who played an inexpensive end-of-life conversation game.

\section{METHODS}

\section{Study Design, Participants, and Setting}

This was a secondary analysis of data collected during a prospective, interventional cohort study, the Hello Project. ${ }^{22}$ The study, which occurred in 53 communities across the USA, examined the impact of an end-of-life conversation game ("Hello") on ACP behaviors and perceptions. A convergent mixed methods approach was used to integrate results from a quantitative questionnaire about values and beliefs related to $\mathrm{ACP}$ with themes identified from qualitative focus groups post-game intervention. The project reached 1,122 participants across 27 states. The project implemented a nationwide community-based delivery model that recruited host organizations to hold game events in their underserved communities. Research assistants traveled to 15 purposively selected African American communities to administer questionnaires and conduct focus groups. Sites were sampled based on community demographics, geographic location, and host organization experience conducting outreach events in underserved African American communities. Host characteristics are shown in Table 1.

Game events were held between May 2018 and November 2018 in 15 states across four US regions: Southern $(n=6$ events), Western ( $n=2$ events), Midwestern ( $n=4$ events), and Northeastern ( $n=3$ events) comprising 10 urban and 4 rural communities. The parent study was designed using Prochaska's trans-theoretical model of behavior change as the underlying conceptual framework. ${ }^{23}$

\section{Intervention}

Events were held at places of worship, community/senior centers, or health centers. The game is played using a previously published booklet of 32 open-ended questions ${ }^{24-26}$ (e.g., "In order to provide you with the best care possible, what 3 non-medical facts should your doctor know about you?'). To play, a player first reads a question to the group, which consists of 4-6 players. Players write their answers and then take turns sharing with the group (or may pass). Conversations emerge as players share their responses. Players control what they share and the group decides when they are ready to move to the next question. To acknowledge a poignant or thoughtful comment, players may give other players a game chip. To promote lighthearted competition, a "winner" is named at the end of the game. A pre-game coin flip (the result is revealed at the game's end) determines whether the "winner" is the player with the most ("heads") or fewest ("tails") chips. Game play continues for up to $60 \mathrm{~min}$.

\section{Procedures and Measures}

Participants completed pre-game measures consisting of baseline demographics and an adapted version of a validated, 7item ACP Value and Beliefs survey (Appendix Text 1). ${ }^{27}$ Next, participants engaged in the end-of-life conversation game, followed by a convenience sample of participants taking part in a focus group. One or two focus groups were held per site with 4-16 participants per site. The interview guide had two sections with open-ended questions and prompts (Appendix Text 2). Section 1 explored the perceived importance of preparing for end-of-life decision-making and asked how participants felt the ACP process should be achieved. Probes explored perceptions of advance directives and the role of faith/spirituality. Section 2 explored the perceived value and impact of the intervention game activity. Trained interviewers conducted the two-part interview (each section lasting $\sim 30$ min), alternating by site which section was completed first. The focus groups were audio-recorded and transcribed verbatim.

Table 1 Purposively Sampled Host Site Demographics

\begin{tabular}{|c|c|c|c|c|c|c|}
\hline Purposively sampled sites $(n=15)$ & Venue type & Region & Urban or rural & No. of attendees & No. consented & Consent rate \\
\hline Lafayette, LA & Place of worship & South & Rural & 43 & 43 & $100 \%$ \\
\hline Sodus, NY & Place of worship & Northeast & Rural & 22 & 22 & $100 \%$ \\
\hline Tuscaloosa, AL & University site & South & Rural & 52 & 50 & $96 \%$ \\
\hline Atlanta, GA & Health center & South & Urban & 35 & 35 & $100 \%$ \\
\hline Philadelphia, PA & Place of worship & Northeast & Urban & 17 & 16 & $94 \%$ \\
\hline Amarillo, TX & Community center & Midwest & Urban & 20 & 20 & $100 \%$ \\
\hline Washington, DC & Place of worship & South & Urban & 48 & 45 & $94 \%$ \\
\hline Las Vegas, NV & Senior center & West & Urban & 39 & 36 & $92 \%$ \\
\hline Lakeland, FL & Health center & South & Urban & 24 & 23 & $96 \%$ \\
\hline Milwaukee, WI & Place of worship & Midwest & Urban & 31 & 18 & $58 \%$ \\
\hline Asheville, NC & Place of worship & South & Rural & 24 & 24 & $100 \%$ \\
\hline Chicago, IL & Place of worship & Midwest & Urban & 32 & 13 & $41 \%$ \\
\hline Battle Creek, MI (excluded) & Place of worship & Midwest & Urban & 6 & 6 & $100 \%$ \\
\hline Palo Alto, CA & Place of worship & West & Urban & 18 & 18 & $100 \%$ \\
\hline St. Louis, MO & Senior center & Midwest & Urban & 17 & 17 & $100 \%$ \\
\hline Total & & & & 428 & 386 & $90 \%$ \\
\hline
\end{tabular}




\section{Justification of Sample Size}

The sample size of this study was decided upon in collaboration with the sponsor, based on the needs of the parent study. A power analysis was not performed because the study was not designed for formal comparisons, but rather to provide regional and geographic diversity of quantitative survey responses. As such, the target sample size for the purposive sample was determined to be 17 communities with 20-50 participants per event.

\section{Statistical Analysis}

A composite overall score for the ACP values and beliefs questionnaire was calculated from the sum of the 7 items. A summative score was calculated only when all 7 items had non-missing responses on the survey. Post hoc comparisons were explored to describe the association between the values and geographical regions. The Wilcoxon rank sum two-sample test was used to assess the difference in scores between the rural and urban responses, and the Kruskal-Wallis test was used when evaluating the difference in regional scores (4 levels). Age was dichotomized as those under the age of 65 and those age 65 or older. We chose a cutoff of 65 as this is a commonly used cutoff and also the point at which additional Medicare benefits permit greater access to primary care (and $\mathrm{ACP}$ ). The Wilcoxon rank sum two-sample test was used to assess the difference in scores between those under the age of 65 and those 65 or older. Venue type was dichotomized as "place of worship" versus "other" and Wilcoxon rank sum two-sample test was used to assess the differences in scores between those two groups. SAS 9.4 was used to perform these two-sided statistical tests using a significance level of 0.05 .

\section{Qualitative Analysis}

Three trained analysts first independently reviewed 6 of the 15 focus group transcripts (chosen for regional and demographic diversity) to define broad categories that were incorporated into a preliminary codebook using the constant comparative method. ${ }^{28}$ Each analyst then coded 3 of the 6 transcripts using this preliminary codebook. Codes were reviewed, discrepancies adjudicated, and the codebook was further refined. The remaining three transcripts were coded using the refined codebook, and an iterative process was used to consolidate codes into a final codebook. Two analysts applied the final codebook to the remaining 9 transcripts. The third analyst reviewed all codes to ensure inter-rater reliability, and extracted themes. The entire team reviewed themes and selected exemplar quotations.

\section{Mixed Methods Analysis}

After analyzing the quantitative and qualitative data independently, conclusions from each dataset were made. We used a compare and contrast approach ("merging") to integrate the data.$^{29}$ To do so, the team first independently and then jointly reviewed both sets of data to assess for convergence or divergence of findings. Conflicts in conclusions were resolved iteratively through group discussions.

\section{IRB Approval}

All procedures were approved by the Penn State College of Medicine Institutional Review Board. The study was registered at clinicaltrials.gov (NCT03456921).

\section{Role of the Funding Source}

This study was funded by the John and Wauna Harman Foundation. The funder was involved in the design of the study cohort but was not involved in data collection, management, analysis, interpretation, or any aspect of the manuscript production

\section{RESULTS}

\section{Participant Characteristics}

Participant characteristics are shown in Table 2. Of the 428 attendees at the events, 386 (90\%) consented to participate in research and $341(88 \%)$ completed all questionnaire items. Participants were primarily African American and female. Most participants (265/380) indicated that religion was extremely important to them. Demographic characteristics were similar between sites, demographics (urban/rural), and region (Appendix Tables 1 and 2).

\section{ACP Values and Beliefs Questionnaire}

On the ACP values and beliefs questionnaire (where $7=$ lowest skepticism and $49=$ highest skepticism), the mean score was 15.27 (SD 9.51) and median score was 12.00, indicating overall low skepticism about ACP prior to game play. There were no statistically significant differences in mean scores based on community region. Rural communities were observed to have more skepticism than urban communities (Table 3), although a 3-point difference on a 42-point scale may not have significant clinical implications. Item by item responses to the survey are shown in Appendix Table 3, with the most agreement with the statement "if you fill out a document such as a living will, the doctors are more likely to "pull the plug' too soon." No statistically significant associations between the values belief score and age (dichotomized as $\geq 65$ or $<65$ ) or venue type ("places of worship" versus "other") were identified.

\section{Thematic Analysis of Focus Group Transcripts}

Three main themes emerged from focus group analysis (Table 4). Notably, within each theme, subthemes emerged highlighting how the conversation game experience 
Table 2 Participant Characteristics from Purposively Sampled Sites $\left(n=380^{*}\right)$

\begin{tabular}{|c|c|}
\hline \multicolumn{2}{|l|}{ Gender, no. (\%) } \\
\hline Female & $304(80)$ \\
\hline No answer & $2(1)$ \\
\hline \multicolumn{2}{|l|}{ Age, Mean (SD) } \\
\hline Years & $\begin{array}{l}62.19 \\
(13.77)^{\dagger}\end{array}$ \\
\hline \multicolumn{2}{|l|}{ Race/ethnicity, no. (\%) } \\
\hline African American & $348(92)$ \\
\hline Native/American Indian & $1(0)$ \\
\hline Hispanic/Latino & $1(0)$ \\
\hline White & $12(3)$ \\
\hline Asian/Pacific Islander & $2(1)$ \\
\hline Other/multiple races indicated & $11(3)$ \\
\hline No answer & $5(1)$ \\
\hline \multicolumn{2}{|l|}{ Annual income, no. $(\%)$} \\
\hline$\leq \$ 10,000$ & $67(18)$ \\
\hline$\$ 20,000$ & $57(15)$ \\
\hline$\$ 30,000$ & $57(15)$ \\
\hline$\$ 40,000$ & $35(9)$ \\
\hline$\$ 50,000$ & $25(7)$ \\
\hline$>\$ 50,000$ & $66(17)$ \\
\hline No answer & 73 (19) \\
\hline \multicolumn{2}{|l|}{ Marital status, no. (\%) } \\
\hline Married/engaged/common-law & $122(32)$ \\
\hline Single & $130(34)$ \\
\hline Divorced/separated & $67(18)$ \\
\hline Widowed & $57(15)$ \\
\hline No answer & $4(1)$ \\
\hline \multicolumn{2}{|c|}{ Highest level of educational attainment, no. (\%) } \\
\hline Did not finish high school & $32(8)$ \\
\hline High school & $77(20)$ \\
\hline Some college & $115(30)$ \\
\hline Associate's degree & $29(8)$ \\
\hline Bachelor's degree & $55(14)$ \\
\hline Graduate degree & $70(18)$ \\
\hline No answer & $2(1)$ \\
\hline \multicolumn{2}{|c|}{ How important is religion or spirituality in your life? no. (\%) } \\
\hline Extremely important & $265(70)$ \\
\hline Very important & $90(24)$ \\
\hline Somewhat important & $19(5)$ \\
\hline Not very important & $2(1)$ \\
\hline Not important at all & $1(0)$ \\
\hline No answer & $3(1)$ \\
\hline \multicolumn{2}{|l|}{ Religious affiliation, no. (\%) } \\
\hline Protestant Baptist & $165(43)$ \\
\hline Protestant other/not specified & $114(30)$ \\
\hline Catholic & $47(12)$ \\
\hline Muslim & $3(1)$ \\
\hline Jewish & $0(0)$ \\
\hline Jehovah's Witness & $3(1)$ \\
\hline Hindu & $1(0)$ \\
\hline \multicolumn{2}{|l|}{ Religious affiliation, no. $(\%)$ cont } \\
\hline Agnostic & $2(1)$ \\
\hline Atheist & $0(0)$ \\
\hline Other & $13(3)$ \\
\hline None & $4(1)$ \\
\hline Prefer not to answer & $13(3)$ \\
\hline No answer & $15(4)$ \\
\hline \multicolumn{2}{|c|}{$\begin{array}{l}\text { Made major medical decisions (i.e., life/death) for another person in the } \\
\text { past } 5 \text { years? no. }(\%)\end{array}$} \\
\hline No & $266(70)$ \\
\hline No answer & $8(2)$ \\
\hline \multicolumn{2}{|c|}{ How would you say your health is in general? no. (\%) } \\
\hline Excellent & $33(9)$ \\
\hline Very good & $188(49)$ \\
\hline Fair & $147(39)$ \\
\hline Poor & $7(2)$ \\
\hline Very poor & $2(1)$ \\
\hline No answer & 3 (1) \\
\hline \multicolumn{2}{|c|}{ Number of hospital admissions in the past 5 years, no. (\%) } \\
\hline 0 & $202(53)$ \\
\hline $1-2$ times & 129 (34) \\
\hline $3-5$ times & $30(8)$ \\
\hline$\geq 6$ times & $9(2)$ \\
\hline No answer & $10(3)$ \\
\hline
\end{tabular}

(continued on next page)

\section{Table 2. (continued)}

\begin{tabular}{ll}
\hline \hline Needs assistance with tasks (select all that apply): No. (\%) \\
Washing/bathing/eating/taking medications/ & $15(4)$ \\
ambulation & $26(7)$ \\
Shopping/going on social outings & $22(6)$ \\
Going to healthcare provider visits & $35(9)$ \\
Organizing finances & $12(3)$ \\
Other & $311(82)$ \\
None/no response & \\
Diagnoses (select all that apply): No. (\%) & $3(1)$ \\
Dementia & $37(10)$ \\
Cancer & $94(25)$ \\
Heart and/or vascular disease & $14(4)$ \\
Lung disease (other than cancer) & $115(30)$ \\
Diabetes & $13(3)$ \\
Kidney disease & $35(9)$ \\
Other & $155(41)$ \\
None/no response & $13(3)$ \\
Autoimmune disease &
\end{tabular}

Categorical values reported as no. (\%). Continuous values reported as Mean (SD) where indicated. See Appendix Text 3 for additional details on data coding and classification

*Excluded $n=6$ from one site due to low attendance resulting in protocol deviation

${ }^{+}$Missing $n=9$

emphasized the need for, and value of, ACP. Example quotations are displayed in Table 4.

Theme 1: There Is a Need for Increased Engagement In, and Knowledge About, ACP. Focus group participants discussed how ACP is an important and valuable process, particularly within their local community groups, recognizing an urgent need to both learn more about ACP and have conversations about end-of-life issues. Participants expressed motivation to have ACP conversations not only to help family members understand the participants' wishes (Theme 1A) but also to learn more about their family members' wishes for their own care (Theme 1B). Participants expressed a desire to understand their family's wishes and preferences, noting that the best way to gain knowledge about these issues is to have conversations with loved ones. The game experience highlighted for participants how and why ACP was needed and valuable to achieve these goals (Theme 1C).

Theme 2: It Is Important to Obtain Legal Documentation Such As Advance Directives and Make Other Final Preparations. Focus group participants frequently included both legal and financial issues into their discussions about why ACP was important, demonstrating that they consider ACP to extend beyond the medical and decision-making aspects of care. ACP was considered essential for planning related to life insurance as well as estate and burial planning (Themes 2A and 2B). The game experience emphasized the need to have these legal and financial documents in place so-as to prevent unnecessary stresses and burdens on loved ones (Theme 2C). 
Table 3 Summative Score* of Values and Belief Survey by Site, Demographic and Region

\begin{tabular}{|c|c|c|c|c|}
\hline & No. & $\begin{array}{l}\text { Mean } \\
\text { (SD) }\end{array}$ & $\begin{array}{l}\text { Median (25th, } \\
\text { 75th percentile) }\end{array}$ & $\begin{array}{l}p \\
\text { value }\end{array}$ \\
\hline \multicolumn{5}{|l|}{ By site } \\
\hline $\begin{array}{l}\text { Livingston, AL ( } \\
=50 \text { ) }\end{array}$ & 42 & $\begin{array}{l}20.90 \\
(1189)\end{array}$ & $\begin{array}{l}20.00(11.00, \\
27.00)\end{array}$ & \\
\hline Palo Alto, CA ( $n$ & 16 & 14.13 & $13.00(7.00$ & \\
\hline $\begin{array}{l}\text { Washington, DC } \\
(n=45)\end{array}$ & 41 & $\begin{array}{l}13.51 \\
(8.15)\end{array}$ & $\begin{array}{l}11.00(7.00, \\
16.00)\end{array}$ & \\
\hline $\begin{array}{l}\text { Lakeland, FL ( } n= \\
23)\end{array}$ & 23 & $\begin{array}{l}10.78 \\
(4.63)\end{array}$ & $\begin{array}{l}10.00(7.00, \\
12.00)\end{array}$ & \\
\hline $\begin{array}{l}\text { Atlanta, GA }(n= \\
35)\end{array}$ & 32 & $\begin{array}{l}17.13 \\
(10.52)\end{array}$ & $\begin{array}{l}13.50(8.50, \\
24.50)\end{array}$ & \\
\hline $\begin{array}{l}\text { Chicago, IL ( } n= \\
\text { 13) }\end{array}$ & 11 & $\begin{array}{l}10.73 \\
(6.18)\end{array}$ & $7.00(7.00,13.00)$ & \\
\hline $\begin{array}{l}\text { Broussard, LA ( } n \\
=43 \text { ) }\end{array}$ & 41 & $\begin{array}{l}14.68 \\
(9.88)\end{array}$ & $\begin{array}{l}12.00(7.00, \\
18.00)\end{array}$ & \\
\hline $\begin{aligned} & \text { St. Louis, MO ( } \\
= & 17)\end{aligned}$ & 16 & $\begin{array}{l}14.63 \\
(13.08)\end{array}$ & $7.50(7.00,16.50)$ & \\
\hline $\begin{aligned} & \text { Asheville, NC ( } n \\
= & 24)\end{aligned}$ & 23 & $\begin{array}{l}13.57 \\
(6.11)\end{array}$ & $\begin{array}{l}13.00(10.00, \\
15.00)\end{array}$ & \\
\hline $\begin{aligned} & \text { Las Vegas, NV ( } n \\
= & 36)\end{aligned}$ & 32 & $\begin{array}{l}16.31 \\
(10.05)\end{array}$ & $\begin{array}{l}13.00(8.00 \\
24.00)\end{array}$ & \\
\hline S2) & 16 & $\begin{array}{l}20.25 \\
(9.79)\end{array}$ & $\begin{array}{l}18.00(12.00, \\
29.00)\end{array}$ & \\
\hline $\begin{array}{l}\text { Philadelphia, PA } \\
(n=16)\end{array}$ & 15 & $\begin{array}{l}15.20 \\
(6.95)\end{array}$ & $\begin{array}{l}12.00(10.00, \\
21.00)\end{array}$ & \\
\hline $\begin{array}{l}\text { Amarillo, TX }(n= \\
20)\end{array}$ & 18 & $\begin{array}{l}10.67 \\
(4.34)\end{array}$ & $8.50(7.00,14.00)$ & \\
\hline $\begin{array}{l}\text { Milwaukee, WI ( } n \\
=18)\end{array}$ & 15 & $\begin{array}{l}14.67 \\
(7.20)\end{array}$ & $\begin{array}{l}13.00(7.00, \\
23.00)\end{array}$ & \\
\hline \multicolumn{5}{|l|}{ By demographic ${ }^{\dagger}$} \\
\hline $\begin{array}{l}\text { Urban sites }(n= \\
241)\end{array}$ & 219 & $\begin{array}{l}14.11 \\
(8.75)\end{array}$ & $\begin{array}{l}11.00(7.00, \\
18.00)\end{array}$ & 0.002 \\
\hline $\begin{array}{l}\text { Rural sites }(n= \\
139)\end{array}$ & 122 & $\begin{array}{l}17.34 \\
(10.46)\end{array}$ & $\begin{array}{l}14.00(8.00, \\
23.00)\end{array}$ & \\
\hline \multicolumn{5}{|l|}{ By region $^{\dagger \dagger}$} \\
\hline $\begin{array}{l}\text { Northeastern sites } \\
(n=83)\end{array}$ & 72 & $\begin{array}{l}15.36 \\
(8.64)\end{array}$ & $\begin{array}{l}13.00(7.50, \\
21.00)\end{array}$ & 0.33 \\
\hline $\begin{array}{l}\text { Southern sites }(n= \\
195)\end{array}$ & 179 & $\begin{array}{l}15.53 \\
(9.80)\end{array}$ & $\begin{array}{l}12.00(7.00, \\
20.00)\end{array}$ & \\
\hline $\begin{array}{l}\text { Midwestern sites } \\
(n=48)\end{array}$ & 42 & $\begin{array}{l}13.62 \\
(9.62)\end{array}$ & $\begin{array}{l}10.00(7.00, \\
17.00)\end{array}$ & \\
\hline $\begin{array}{l}\text { Western sites }(n= \\
54)\end{array}$ & 48 & $\begin{array}{l}15.58 \\
(9.72)\end{array}$ & $\begin{array}{l}13.00(7.50, \\
19.50)\end{array}$ & \\
\hline \multicolumn{5}{|l|}{ By age } \\
\hline $\begin{array}{l}>65 \text { years }(n= \\
180)\end{array}$ & 158 & $\begin{array}{l}15.32 \\
(9.97)\end{array}$ & $\begin{array}{l}12.00(7.00, \\
20.00)\end{array}$ & 0.50 \\
\hline $\begin{array}{l}<65 \text { years }(n= \\
181)\end{array}$ & 170 & $\begin{array}{l}15.34 \\
(9.32)\end{array}$ & $\begin{array}{l}12.50(8.00 \\
20.00)\end{array}$ & \\
\hline \multicolumn{5}{|l|}{ By venue type } \\
\hline $\begin{array}{l}\text { Place of worship } \\
(n=199)\end{array}$ & 178 & $\begin{array}{l}16.09 \\
(10.52)\end{array}$ & $\begin{array}{l}13.00(7.00, \\
22.00)\end{array}$ & 0.47 \\
\hline Other $(n=181)$ & 163 & $\begin{array}{l}14.52 \\
(8.44)\end{array}$ & $\begin{array}{l}12.00(7.00, \\
18.00)\end{array}$ & \\
\hline Overall $(n=380)$ & 341 & $\begin{array}{l}15.27 \\
(9.51)\end{array}$ & $\begin{array}{l}12.00(7.00, \\
20.00)\end{array}$ & \\
\hline
\end{tabular}

*Summative score ranges 7-49, where $7=$ least skeptical of $A C P, 49=$ most skeptical of ACP

${ }^{*}$ Wilcoxon rank sum normal approximation $p$ value $=0.002$

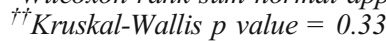

Theme 3: Among African Americans, Community Networks Have an Important Role in Facilitating ACP Activities, with Emphasis on Church and Faith-Based Networks. Participants felt strongly that the community places of worship have an important role in spreading information, resources, and opportunity for engagement in ACP (Theme 3A). These community networks were mentioned organically (without prompting) and were disproportionately emphasized when compared with the role healthcare providers. Furthermore, the role of the shared community and peer experience through storytelling and shared perspectives was considered important and valuable as a part of ACP (Theme 3B) and the opportunity for learning from others' experiences was highlighted by the game experience (Theme 3C).

\section{Mixed Methods Integration}

The quantitative and qualitative datasets were convergent regarding African Americans' views about ACP. That is, the conclusions drawn from each separate analysis were similar. Specifically, the quantitative questionnaire data demonstrated low levels of skepticism/negative attitudes about ACP, while qualitative data revealed positive perceptions/opinions about the benefits of ACP.

\section{CONCLUSIONS}

Contrary to current literature, in this secondary analysis of a large, national sample of African Americans (prior to engagement in an ACP intervention), participants reported low levels of skepticism toward ACP. This is an important finding because the low prevalence of ACP in African American communities is commonly attributed to skepticism/negative attitudes about the process. ${ }^{2,5,30}$ In contrast, this study revealed overwhelmingly positive attitudes about ACP, and the importance/value of advance directives in particular. The authenticity of these findings is further reinforced by the high levels of subsequent ACP-related behavior such as completion of an advance directive or discussion with a family member (reported separately). ${ }^{31}$

Notably, we did not identify any consistent regional or geographic variation in ACP-related values and beliefs in either the quantitative or qualitative data, although rural communities reported more skepticism than urban communities. That said, it is possible that our findings may be somewhat attributed to selection bias towards those inclined to attend community-based ACP activities or towards those with strong religious faith (as in our sample). It is also possible that nationwide campaigns and advocacy initiatives have begun to move the needle regarding attitudes about ACP.

Our qualitative findings also identified the important role of activities that prompt conversations about values and beliefs as they relate to ACP. Prior research on the serious game Hello established that using an end-of-life conversation game stimulates a safe and non-threatening context for having sensitive discussions about death and motivates performance of subsequent ACP behaviors. ${ }^{25,}{ }^{32-34}$ Themes from the present study's post-game focus groups further reinforce the value of a community-based (rather than healthcare-based) model for engaging African American communities in ACP. Specifically, participants noted that sharing of views and hearing the 
Table 4 Themes from Post-Intervention Focus Groups with Quotations*

\section{Theme 1: There is a need for increased ACP knowledge and engagement}

\section{$\begin{array}{ll}\text { Subtheme } & \text { Quotation }\end{array}$}

(1A) Recognizing the urgency of ACP for oneself We tend to place an age on death and there is no age on death and so my awareness

(1B) Recognizing the need for ACP for one's family

from today is that it needs to start early rather than later.

...I would like to get my family members together and let them discuss it all with me so that they will all be in agreement as to what I want, you know, for myself, if I am not able to do it, so there won't be any one [who] wanted it this way and the other wanted it that way - to make a decision with me present [so] it's agreeable with me too. That's what I would like.

(1C) The game was engaging and helped emphasize the need and value of ACP

I just learned a lot. I definitely saw the urgency and these are not subjects that I think a whole lot about and I realize, that's bad...that's not good at all...it starts today and we need to get ready today.

Theme 2: It is important to obtain legal documentation such as advance directives and make other final preparations

Subtheme

(2A) Financial planning and insurance matters

(2B) Funeral and burial matters

(2C) The game emphasized the need to have legal documents and financial arrangements in place

Theme 3: The Subtheme

(3A) Role of the church and/or community

(3B) There is value in storytelling and sharing perspectives with peers and community

\section{Subtheme cont}

(3C) The game allowed participants to learn from one another's experiences and stories

\section{Quotation}

...in communities where there are a lot of disparities that's out there, we don't want to talk about that piece, talk about life insurance [because everyone will think] you must be about to pass away... as a community we have to get through [that] and get rid of that barrier because, at the end of the day, if we really appreciate those in our lives and those who remain...I wouldn't want my family to stress on things that I have...[I'd] like to have my stuff in order before then.

... Not to get the race or anything but we as a group of African Americans need to get things in order. This would help to get things in order, you know, for their final states... it would also get people done saying you're going to leave here and you've got to either be cremated or buried-nothing bothers me more when I hear someone is having a car wash to raise money... this would help a lot of people realize that [they] need to get this taken care of.

... this is a starting point for the majority of us. We know that we need to get things in order but we just put it off, I'll do that later, but now [I need to] to go ahead and to make our wishes known and to get it written down on paper so that when we cannot speak then our wishes will be known and our loved ones will know what to do and what they have to do.. I thank those who organized [the game] and I will put my wishes on paper.

\section{rocess}

\section{Quotation}

I think that this type of program is how the church can prepare us outside of the spiritual aspect of it is making members aware of different things that that are going on in a community that has to deal with talking about this topic.... I think by giving the message of having members attend things like this in nature that's how they get educate us on the other aspect besides spiritually.

This has been an interesting experience. Especially in the individuals that are here, a chance to talk about their experiences as far as the loss of their loved ones....it was a way that you could help the healing process and the more that you talk to someone about the experiences that you have, I think that's one way the you can help with the grieving process because we all grieve in different ways. It's all right to grieve and I think we as African Americans are learning more how to grieve and how to grieve is accepted more and in the same way, the experiences that we had and I think this is a valuable experience for us as a race of people to become more aware of how we can be supportive of each other...

Quotation cont

...what I like from it was hearing everyone else's answers because even though I knew what I was going to put down, it got me to think of - hmmm maybe I should have thought it from this perspective or I did I even think about that so it gives you something different to think about besides what you feel you would do.

*Some quotations have been minimally edited for brevity and clarity

perspectives of peers was highly valued in this community — not only for informing their viewpoints but also confirming the importance of ACP. Participants expressed high satisfaction and endorsement of the activity, moving them to engage in ACP behaviors (reported separately). ${ }^{31}$

This study has several limitations. First, our sample consisted of participants who chose to attend a community event that featured a conversation game dealing with endof-life issues, and therefore our results are subject to selection bias. It is possible that participants held a more positive attitude toward ACP than non-participants, and if this is the case, our findings might overestimate the level of enthusiasm for advance care planning in the general population. Second, the study questionnaire did not explore trust in the healthcare system in general, or baseline knowledge about ACP - variables that could have an impact on the main outcomes. Though our study was grounded in Prochaska's trans-theoretical model of behavior change (as per the parent study design), future studies might benefit from additional theoretical frameworks that incorporate the interrelationship between knowledge, attitudes, and beliefs. Third, due to administrative error, the scale was reversed from the original, validated version. Fourth, while our findings of strong convergence between qualitative and quantitative data support the validity of the quantitative survey data, this may be, in part, because we sampled the qualitative cohort from the original quantitative cohort. Finally, as a secondary analysis nested within a larger cohort study, the absence of regional 
variability in the present findings must be viewed with caution as the study was not powered to conduct sample site comparisons.

That said, our study has many strengths, including its large sample size, national scope, and regional diversity. Furthermore, this study's use of a convergent, mixed methods design, and high concordance across datasets strengthens the credibility and validity of the findings. ${ }^{35}$ In conclusion, this study revealed that African American study participants across the USA have positive attitudes about ACP, and assign value and importance to the ACP process of creating advance directives. This finding is contrary to commonly held beliefs that this population is skeptical and distrusting of ACP and/or advance directives.

Acknowledgments: The authors would like to thank all the host organizations who participated in the Hello Project nationwide. The authors would like to acknowledge the following individuals for assistance with data collection, entry and management: Katherine Callahan, Kayla Confer, Lindsey Currin, James Harness, Margaret Hopkins, Meghan Lee, Anna R. Levi, Yining Ma, Sara Marlin, Nicole Matluck, Timothy Sheehan, and Xingran Wren. We would also like to acknowledge the Hello Project Advisory Board. We thank Dr. Andrew Foy for critical review of the manuscript and we thank Common Practice, LLC for permission to use their game Hello.

Corresponding Author: Lauren Jodi Scoy, MD; Department of Medicine, Penn State College of Medicine, Hershey, PA, USA (e-mail: lvanscoy@pennstatehealth.psu.edu).

Funding Research reported in this project was funded by the John and Wauna Harman Foundation. Dr. Van Scoy has received funding from the National Institute of Health, Canadian Institute of Health Research, Society for Critical Care Medicine, the Francis Family Foundation, and Association for Clinical Pastoral Education. Dr. Levi has received funding from the National Institute of Health and Children's Miracle Network. Dr. Green has received funding from the National Institute of Health. Dr. Chinchilli has received funding from the National Institute of Health and Patient Centered Outcomes Research Institute. Some authors may have additional funding sources unrelated to the subject matter of this manuscript and is available upon request. The REDCap database used in this project was funded by The Penn State Clinical \& Translational Research Institute, Pennsylvania State University CTSA, NIH/NCATS Grant Number UL1 TROOO127 and UL1 TROO2014.

\section{Compliance with Ethical Standards:}

Conflict of Interest: Dr. Van Scoy reported serving as an unpaid scientific advisor to Common Practice, LLC. Drs. Green and Levi are consultants for Vital Decisions, the parent company that owns the electronic version of the advance directive used in this study (My Living Voice). Vital Decisions provided permission to reproduce paper copies of My Living Voice. No other authors have conflicts of interest to disclose related to this research.

\section{REFERENCES}

1. Sudore RL, Lum HD, You JJ, Hanson LC, Meier DE, Pantilat SZ, et al Defining Advance Care Planning for Adults: A Consensus Definition From a Multidisciplinary Delphi Panel. J Pain Symptom Manag. 2017;53(5):821-32 el. https://doi.org/10.1016/j.jpainsymman.2016 12.331
2. Dying in America: Improving Quality and Honoring Individual Preferences Near the End of Life. book. Washington, DC: The Institute of Medicine 2014.

3. Rao JK, Anderson LA, Lin FC, Laux JP. Completion of advance directives among U.S. consumers. Am J Prev Med. 2014;46(1):65-70. https://doi.org/10.1016/j.amepre.2013.09.008.

4. Koss CS, Baker TA. Race differences in advance directive completion: the narrowing gap between White and African American older adults. J Aging Health. 2017;29(2):324-42.

5. Sanders JJ, Robinson MT, Block SD. Factors Impacting Advance Care Planning among African Americans: Results of a Systematic Integrated Review. J Palliat Med. 2016;19(2):202-27. https://doi.org/10.1089/jpm. 2015.0325 .

6. Harrison KL, Adrion ER, Ritchie CS, Sudore RL, Smith AK. Low Completion and Disparities in Advance Care Planning Activities Among Older Medicare Beneficiaries. JAMA Intern Med 2016;176(12):1872-5. https://doi.org/10.1001/jamainternmed.2016.6751.

7. LoPresti MA, Dement F, Gold HT. End-of-life care for people with cancer from ethnic minority groups: a systematic review. Am J Hosp Palliat Med. 2016;33(3):291-305

8. Mack JW, Paulk ME, Viswanath K, Prigerson HG. Racial disparities in the outcomes of communication on medical care received near death. Arch Intern Med. 2010;170(17):1533-40.

9. Cohen LL. Racial/ethnic disparities in hospice care: a systematic review. J Palliat Med. 2008;11(5):763-8. https://doi.org/10.1089/jpm.2007. 0216.

10. Block BL, Jeon SY, Sudore RL, Matthay MA, Boscardin WJ, Smith AK. Patterns and Trends in Advance Care Planning Among Older Adults Who Received Intensive Care at the End of Life. JAMA Intern Med. 2020;180(5):786-9. https://doi.org/10.1001/jamainternmed.2019. 7535.

11. Hong M, Yi EH, Johnson KJ, Adamek ME. Facilitators and Barriers for Advance Care Planning Among Ethnic and Racial Minorities in the U.S.: A Systematic Review of the Current Literature. J Immigr Minor Health. 2018;20(5):1277-87. https://doi.org/10.1007/s10903-017-0670-9.

12. Nicholas LH, Langa KM, Iwashyna TJ, Weir DR. Regional Variation in the Association Between Advance Directives and End-of-Life Medicare Expenditures. JAMA. 2011;306(13):1447-53.

13. Zhang B, Wright AA, Huskamp HA, Nilsson ME, Maciejewski ML, Earle CC, et al. Health care costs in the last week of life: associations with end-of-life conversations. Arch Intern Med. 2009;169(5):480-8.

14. Martin RS, Hayes B, Gregorevic K, Lim WK. The Effects of Advance Care Planning Interventions on Nursing Home Residents: A Systematic Review. J Am Med Dir Assoc. 2016;17(4):284-93. https://doi.org/10. 1016/j.jamda.2015.12.017.

15. O'Hanlon CE, Walling AM, Okeke E, Stevenson S, Wenger NS. A Framework to Guide Economic Analysis of Advance Care Planning. J Palliat Med. 2018;21(10):1480-5. https://doi.org/10.1089/jpm.2018. 0041.

16. Silveira MJ, Wiitala W, Piette J. Advance directive completion by elderly Americans: a decade of change. J Am Geriatr Soc. 2014;62(4):706-10. https://doi.org/10.1111/jgs. 12736.

17. Silveira MJ, Kim SYH, Langa KM. Advance directives and outcomes of surrogate decision making before death. $N$ Engl J Med. 2010;362(13):1211-8.

18. Resnick HE, Hickman S, Foster GL. Documentation of Advance Directives Among Home Health and Hospice Patients: United States, 2007. Am J Hosp Palliat Care. 2012;29(1):26-35.

19. Bischoff KE, Sudore R, Miao Y, Boscardin WJ, Smith AK. Advance care planning and the quality of end-of-life care in older adults. J Am Geriatr Soc. 2013;61(2):209-14. https://doi.org/10.1111/jgs. 12105.

20. Wicher CP, Meeker MA. What influences African American end-of-life preferences? J Health Care Poor Underserved 2012;23(1):28-58. https:// doi.org/10.1353/hpu.2012.0027.

21. Ladd SC. Systematic Review of Research Literature on African Americans' End-of-Life Healthcare Preferences. J Afr Am Stud. 2014;18(4):373-97. https://doi.org/10.1007/s12111-013-9276-z.

22. Van Scoy LJ, Levi BH, Witt P, Bramble C, Richardson C, Putzig I, et al. Association of Participation in an End-of-Life Conversation Game With Advance Care Planning Behavior and Perspectives Among African American Individuals. JAMA Netw Open. 2020;3(5):e204315. https:// doi.org/10.1001/jamanetworkopen.2020.4315

23. Prochaska JO, Velicer WF. The transtheoretical model of health behavior change. Am J Health Promot. 1997; 12(1):38-48.

24. Van Scoy LJ, Reading JM, Scott AM, Chuang C, Levi BH, Green MJ. Exploring the Topics Discussed During a Conversation Card Game About 
Death and Dying: A Content Analysis. J Pain Symptom Manag 2016;52(5):655-62. https://doi.org/10.1016/j.jpainsymman.2016.03.021.

25. Van Scoy LJ, Reading JM, Scott AM, Green MJ, Levi BH. Conversation Game Effectively Engages Groups of Individuals in Discussions about Death and Dying. J Palliat Med. 2016;19(6):661-7. https://doi.org/10. 1089/jpm.2015.0390

26. Van Scoy LJ, Watson-Martin E, Bohr TA, Levi BH, Green MJ. End-ofLife Conversation Game Increases Confidence for Having End-of-Life Conversations for Chaplains-in-Training. Am J Hosp Palliat Care 2017:1049909117723619. https://doi.org/10.1177/ 1049909117723619.

27. Fried TR, Redding CA, Robbins ML, Paiva A, O'Leary JR, Iannone L. Promoting advance care planning as health behavior change: development of scales to assess Decisional Balance, Medical and Religious Beliefs, and Processes of Change. Patient Educ Couns 2012;86(1):25-32. https://doi.org/10.1016/j.pec.2011.04.035.

28. Glaser BG. The constant comparative method of qualitative analysis. Soc Probl. 1965; 12(4):436-45.

29. Fetters MD, Curry LA, Creswell JW. Achieving integration in mixed methods designs-principles and practices. Health Serv Res. 2013;48(6 Pt 2):2134-56. https://doi.org/10.1111/1475-6773.12117.

30. Ko E, Lee $\mathbf{J}$. Completion of advance directives among low-income older adults: Does race/ethnicity matter? Am J Hosp Palliat Med. 2014;31(3):247-53.
31. Van Scoy LJ, Levi BH, Witt P, Bramble C, Richardson C, Putzig I, Levi A, Wasserman E, Chinchilli VM, Tucci A, Green MJ. End-of-life conversation game motivates underserved African Americans to engage in advance care planning- a national, prospective mixed methods cohort study. Pending Publication, JAMA Open Network. 2019.

32. Radhakrishnan K, Van Scoy LJ, Jillapalli R, Saxena S, Kim MT. Community-based game intervention to improve South Asian Indian Americans' engagement with advanced care planning. Ethn Health 2017:1-19. https://doi.org/10.1080/13557858.2017.1357068.

33. Van Scoy LJ, Green MJ, Reading JM, Scott AM, Chuang CH, Levi BH. Can Playing an End-of-Life Conversation Game Motivate People to Engage in Advance Care Planning? Am J Hosp Palliat Care 2017;34(8):754-61. https://doi.org/10.1177/1049909116656353.

34. Van Scoy LJ, Reading JM, Hopkins M, Smith B, Dillon J, Green MJ, et al. Community Game Day: Using an End-of-Life Conversation Game to Encourage Advance Care Planning. J Pain Symptom Manag. 2017;54(5):680-91. https://doi.org/10.1016/j.jpainsymman.2017.07. 034

35. Creswell Jw, Creswell JD. Research design: Qualitative, quantitative, and mixed methods approaches: Sage publications. 2017.

Publisher's Note: Springer Nature remains neutral with regard to jurisdictional claims in published maps and institutional affiliations. 